\title{
Parametric Optimization of Single Cylinder Diesel Engine for Pyrolysis Oil and Diesel Blend for Specific Fuel Consumption Using Taguchi Method
}

\author{
Mr. Krunal B Patel ${ }^{1}$, Prof. Tushar M Patel ${ }^{2}$, Mr. Saumil C Patel ${ }^{3}$ \\ ${ }^{1}$ ME Scholar, L.D.R.P engineering college, Gandhinagar, India. \\ ${ }^{2}$ Asso.Prof. in L.D.R.P engineering college, Gandhinagar, India. \\ ${ }^{3}$ Research Scholar, PAHER University, Udaipur, India.
}

\begin{abstract}
An experimental study has been carried out for pyrolysis oil blended with diesel used in single cylinder diesel engine. Pyrolysis oil is obtained from tire waste by pyrolysis process. Pyrolysis process is a thermo-chemical decomposition of organic matter in absence of oxygen. Blending of pyrolysis oil with diesel in maximum possible proportion helps to reduce the consumption of diesel fuel. In this study, the effects of parameters i.e. injection timing, injection pressure, compression ratio, and load are taken as variable for optimization. As the experiment required simultaneously optimization of four parameters with five levels, taguchi method of optimization is used in this experiment. The results of the taguchi experiment identifies that $22^{0}$ injection timing, injection pressure 200 bar, compression ratio 16 and engine load $20 \mathrm{~kg}$ are optimum parameter setting for lowest break specific fuel consumption. Engine performance is mostly influenced by engine load and is least influenced by Compression ratio.
\end{abstract}

Keyword: Pyrolysis oil, SFC, Taguchi Analysis, CI engine, Diesel

\section{Introduction}

In present position of the world, energy crisis due to fast depletion of fossil fuel is main problem. Increase in fuel price day by day, continuously growth of automobile industry, rapid growth in individual mobility and improved living standard, continuous accumulation of greenhouse gases are the main causes for development of alternative fuels. In present situation, there is much possibility of multifold increase in the research in biodiesel, vegetable oils like soybean oil, rapseed oil, sunflower oil, methanol, ethanol and other alternate fuels. Considering alternate fuels as a substitute of diesel, Researchers are continuously finding best alternative solution, which gives the best performance and fuel characteristics. Most of alternative fuels used today are biodiesel or bio ethanol which can be used in existing engines. The primary advantage of this kind of fuel is that they are renewable and eco-friendly. The various techniques for admission of fuel and mixing of alternate fuel with diesel are required. Recently in this field, the research work is going on to increase maximum portion of alternate fuel in blend with diesel. With the use of alternate fuels, main issue is modification required in IC engines. In order to reduce cost of modification some optimization techniques must be applied. So that efficiency and performance may not be reduced. In such multivariate problem, use of non linear techniques like Design of Experiments (DOE), fuzzy logic and neural network are suitable to explore the combined effects of input parameters. The optimum operating parameters for a given system can be determined using experimental techniques but experimental procedure will be time consuming and expensive when the number of parameters are in the order of 20, 30 etc., like in the case of IC engines. In such situations mathematical modeling will be a very useful tool for optimizing the parameters. Such a mathematical tool is Design of Experiment. Although few studies were reported using DOE in IC Engine applications, the study on combined effects between input system parameters such as injection pressure, load, blend proportion on the performance and emission characteristics of $\mathrm{CI}$ engine was scarce and offered a scope for this study.

\section{Pyrolysis Oil}

Pyrolysis oil is obtained from tire waste by process which is called pyrolysis process. It is a thermochemical decomposition of organic matter in absence of oxygen. Pyrolysis of waste vehicle tires with the purpose of fuel production for the usage as a fuel in internal combustion engine can be seen as a hygienic, environmentally acceptable and efficient way of disposing them. In an experimental study, it was reported that, cross-section samples of 2-3 cm wide, representative of a whole car tire, have been pyrolysed under nitrogen in a $3.5 \mathrm{dm} 3$ autoclave at $300,400,500,600$ and $700{ }^{\circ} \mathrm{C}$. At over $500{ }^{\circ} \mathrm{C}$ there is no effect of temperature on gas and liquid yields which were about $17 \%$ and $38 \%$, respectively. Besides, catalysts have been applied in several studies for upgrading the quality and quantity of the products obtained from waste tire pyrolysis. Tire pyrolysis 
oil derived from waste automobile tires was analyzed and compared with the petroleum products and was found that it can also be used as a fuel for compression ignition engine.

It was reported that pyrolysis of scrap tyres produced oil similar in properties to a light fuel oil, with similar calorific value, and sulphur and nitrogen contents. The oil was found to contain $1.4 \%$ sulphur and $0.45 \%$ nitrogen by mass, and had similar properties to diesel fuel. The oil contained a significant concentration of polycyclic aromatic hydrocarbons, some of which had been shown to be carcinogenic and/or mutagenic. A single oil droplet combustion study was carried out and also the oil was analyzed in detail for its content of polycyclic aromatic hydrocarbons (PAH). The derived oil was combusted in a $18.3 \mathrm{~kW}$ ceramic-lined, oil-fired, spray burner furnace, $1.6 \mathrm{~m}$ in length and $0.5 \mathrm{~m}$ internal diameter. The emissions of NOx, SO2, particulate and total unburned hydrocarbons were determined in relation to excess oxygen levels. Throughout the combustion tests, comparison of the emissions was made with the combustion of diesel. The oil was found to contain $1.4 \%$ sulphur and $0.45 \%$ nitrogen on mass basis and have similar fuel properties to those of DF.

\section{Experimental Setup}

The setup consists of single cylinder, four stroke, multi-fuel, research engine connected to eddy type dynamometer for loading. The operation mode of the engine can be changed from diesel to Petrol of from Petrol to Diesel with some necessary changes. In both modes the compression ration can be varied without stopping the engine and without altering the combustion chamber geometry by specially designed tilting cylinder block arrangement. The injection point and spark point can be changed for research tests. Setup is provided with necessary instruments for combustion pressure, Diesel line pressure and crank-angle measurements. These signals are interfaced with computer for pressure crank-angle diagrams. Instruments are provided to interface airflow, fuel flow, temperatures and load measurements. The set up has stand-alone panel box consisting of air box, two fuel flow measurements, process indicator and hardware interface. Rota meters are provided for cooling water and calorimeter water flow measurement. A battery, starter and battery charger is provided for engine electric start arrangement.

The setup enables study of VCR engine performance for brake power, indicated power, frictional power, BMEP, IMEP, brake thermal efficiency, indicated thermal efficiency, Mechanical efficiency, volumetric efficiency, specific fuel consumption, A/F ratio, heat balance and combustion analysis. Lab view based Engine Performance Analysis software package "Engine soft" is provided for on line performance evaluation. Table.1 shows Technical specification of C.I Engine.

Table.1 Technical Specifications

\begin{tabular}{|l|l|}
\hline Item & Specification \\
\hline Model & TV1 \\
\hline Make & Kirlosker Oil Engines \\
\hline Type & Four stroke, Water cooled, Diesel \\
\hline No. of cylinder & One \\
\hline Bore & $87.5 \mathrm{~mm}$ \\
\hline Stroke & $110 \mathrm{~mm}$ \\
\hline Compression ratio & 12 to 18 \\
\hline Power rating & $7.5 \mathrm{HP}$ \\
\hline Injection timing & $\leq 25^{\circ}$ BTDC \\
\hline
\end{tabular}

IV. Methodology

Bi-fueling or blending is the simplest technique for admitting low cetane fuels in high compression engines. According to Dhanajay Joshi et.al 5\% blend of pyrolysis oil with diesel gives best result for the mechanical efficiency [1]. In this experiment the pyrolysis oil is mixed with standard diesel oil in 5\% proportions on volume basis and its properties such as calorific value and viscosity were evaluated before admission. In this study, the effects of parameters` i.e. injection timing, injection pressure, compression ratio, and load are taken as variable for optimization. A method called 'Taguchi' was used in the experiment for simultaneous optimization of engine parameters such as injection timing, injection pressure, compression ratio, and load etc.

Taguchi method is a simplest method of optimizing experimental parameters in less number of trials. The number of parameters involved in the experiment determines the number of trials required for the experiment. More number of parameters led to more number of trials and consumes more time to complete the experiment. Hence, a method called 'Taguchi' was tried in the experiment to optimize the levels of the parameter involved in the experiment. This method uses an orthogonal array to study the entire parameter space with only a small number of experiments. The present study uses four factors at five levels and hence, an L25 
orthogonal array with four columns and twenty five rows were used for the construction of experimental layout. Table. 2 shows, L25 has four columns and twenty five rows and the parameters such as injection timing, injection pressure and compression ratio and load are arranged in column 1,2,3 and 4. According to this layout, twenty five experiments were designed and trials were selected at random, to avoid systematic error creeping into the experimental procedure. For each trial the brake specific fuel consumption was calculated and used as a response parameter. Taguchi method uses a parameter called signal to noise ratio $(\mathrm{S} / \mathrm{N})$ for measuring the quality characteristics. There are three kinds of signal to noise ratios are in practice. Of which, the lower-thebetter $\mathrm{S} / \mathrm{N}$ ratio was used in this experiment because this optimization is based on lower SFC. The taguchi method used in the investigation was designed by statistical software called 'Minitab Release 16' to simplify the taguchi procedure and results. A full range experiment for the selected blend was also conducted for after modifying the engine operating parameters. This is mainly to optimize the performance characteristics of pyrolysis oil-diesel blend.

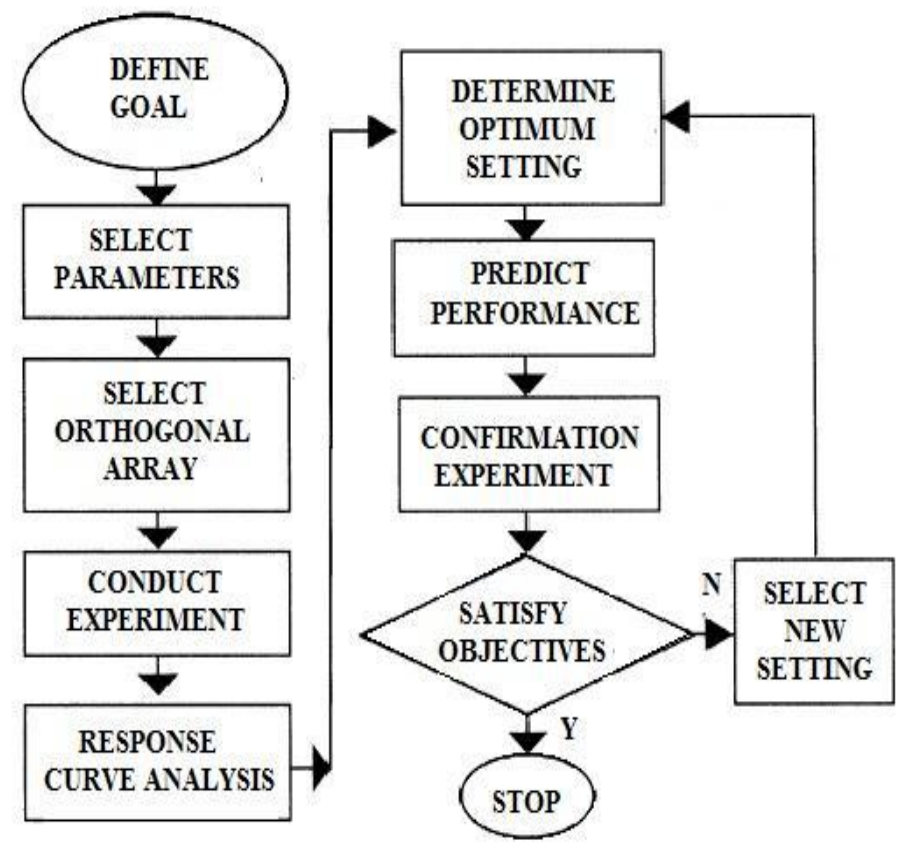

Fig.1 Flow chart of the Taguchi method

\section{Results And Discussion}

Experiment was done for selected sets of parameters by Minitab software and find Break Specific Fuel Consumption (BSFC) for those sets of parameters. Break Specific Fuel Consumption (BSFC) for those sets are given in the table.2

Table.2 L25 Orthogonal array

\begin{tabular}{|c|c|c|c|c|c|}
\hline SR. NO & $\begin{array}{c}\text { INJECTION } \\
\text { TIMING } \\
\text { (DEGREE) }\end{array}$ & $\begin{array}{c}\text { INJECTION } \\
\text { PRESSURE } \\
\text { (Bar) }\end{array}$ & $\begin{array}{c}\text { LOAD } \\
\text { (KG) }\end{array}$ & $\begin{array}{c}\text { COMPRESSION } \\
\text { RATIO }\end{array}$ & $\begin{array}{c}\text { SFC } \\
\text { (KG/KWH) }\end{array}$ \\
\hline 1 & 20 & 140 & 0.98 & 14.00 & 3.16 \\
\hline 2 & 20 & 160 & 1.91 & 15.00 & 1.38 \\
\hline 3 & 20 & 180 & 3.01 & 16.00 & 1.26 \\
\hline 4 & 20 & 200 & 3.82 & 17.00 & 1 \\
\hline 5 & 20 & 220 & 4.82 & 18.00 & 0.79 \\
\hline 6 & 22 & 160 & 2.93 & 14.00 & 0.87 \\
\hline 7 & 22 & 180 & 3.94 & 15.00 & 0.69 \\
\hline 8 & 22 & 200 & 4.79 & 16.00 & 0.61 \\
\hline 9 & 22 & 220 & 0.97 & 17.00 & 2.24 \\
\hline 10 & 22 & 140 & 1.94 & 18.00 & 1.21 \\
\hline 11 & 23 & 180 & 4.90 & 14.00 & 0.61 \\
\hline 12 & 23 & 200 & 0.92 & 15.00 & 4.55 \\
\hline
\end{tabular}




\begin{tabular}{|c|c|c|c|c|c|}
\hline 13 & 23 & 220 & 1.96 & 16.00 & 1.06 \\
\hline 14 & 23 & 140 & 2.94 & 17.00 & 0.7 \\
\hline 15 & 23 & 160 & 3.92 & 18.00 & 0.53 \\
\hline 16 & 24 & 200 & 1.76 & 14.00 & 1.34 \\
\hline 17 & 24 & 220 & 3.02 & 15.00 & 0.73 \\
\hline 18 & 24 & 140 & 3.89 & 16.00 & 0.61 \\
\hline 19 & 24 & 160 & 4.86 & 17.00 & 0.52 \\
\hline 20 & 24 & 180 & 0.91 & 18.00 & 1.59 \\
\hline 21 & 25 & 220 & 4.09 & 14.00 & 1.25 \\
\hline 22 & 25 & 140 & 5.09 & 15.00 & 0.95 \\
\hline 23 & 25 & 160 & 0.93 & 16.00 & 4.73 \\
\hline 24 & 25 & 180 & 1.90 & 17.00 & 1.12 \\
\hline 25 & 25 & 200 & 2.96 & 18.00 & 0.72 \\
\hline
\end{tabular}

\subsection{Response Curve analysis}

Response curve analysis is aimed at determining influential parameters and their optimum levels. It is graphical representations of change in performance characteristics with the variation in process parameter. The curve give a pictorial view of variation of each factor and describe what the effect on the system performance would be when a parameter shifts from one level to another. Figure-4 shows significant effects for each factor for five levels.

The $\mathrm{S} / \mathrm{N}$ ratio for the performance curve were calculated at each factor level and average effects were determined by taking the total of each factor level and dividing by the number of data points in the total. The greater difference between levels, the parametric level having the lowest $\mathrm{S} / \mathrm{N}$ ratio corresponds to the parameters setting indicates highest performance.

From fig.2, mean is average value for reading taken for particular parameter. From graph, mean value is maximum (1.7540) for 250 BTDC injection timing and minimum (0.9580) for 240 BTDC injection timing. Mean value is maximum (1.6600) for 160 bar injection pressure and minimum (0.9680) for 220 bar injection pressure. Mean value is maximum (1.6440) for 17 compression ratio and minimum (1.0540) for 16 compression ratio. Mean value is maximum (3.2540) for $1 \mathrm{~kg}$ engine load and minimum (0.6960) for $5 \mathrm{~kg}$ engine load.

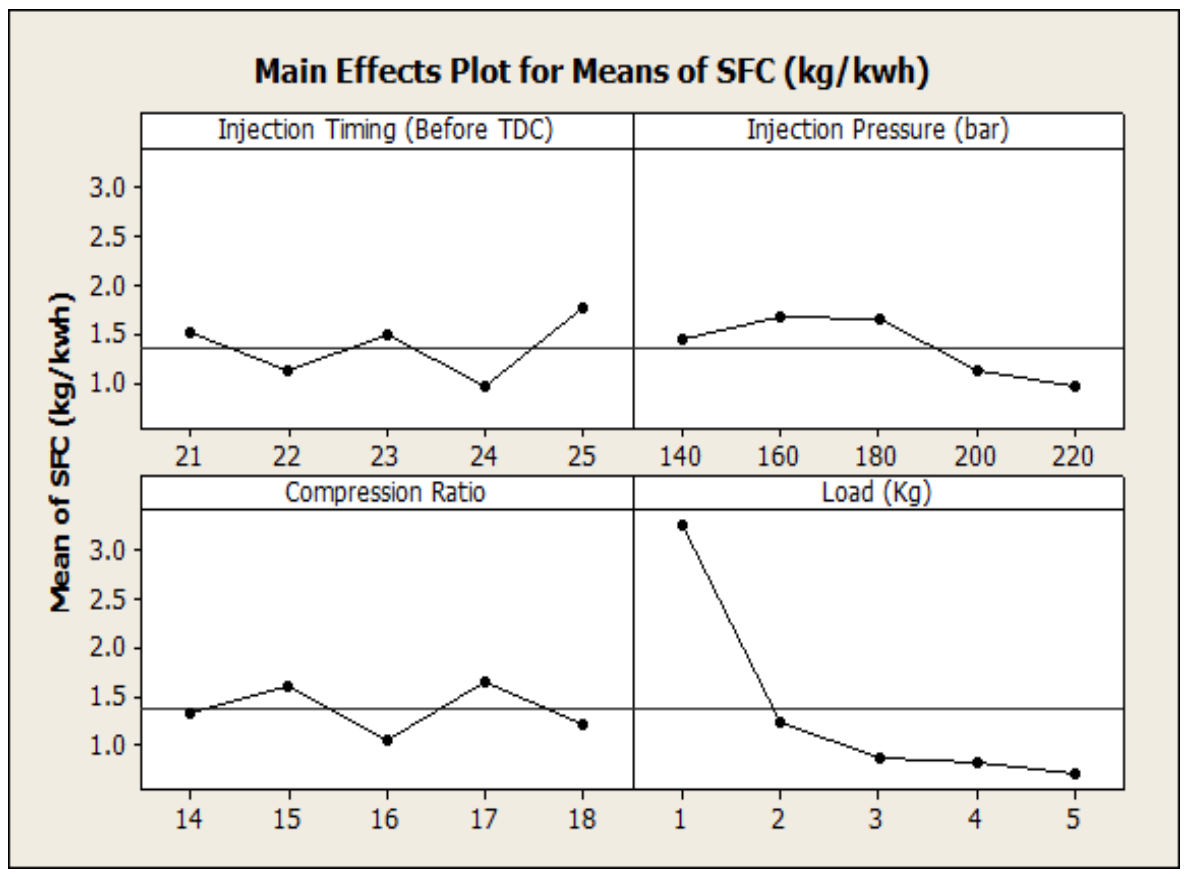

Fig.2 Main effects of parameter

Delta is difference of maximum value and minimum value. Delta value is maximum for load (2.5580) and minimum (0.5900) for compression ratio parameter. Delta value for Injection timing and injection pressure are between other two parameter. So that effect of load is maximum and effect of compression ratio is minimum on Specific fuel consumption (SFC). 


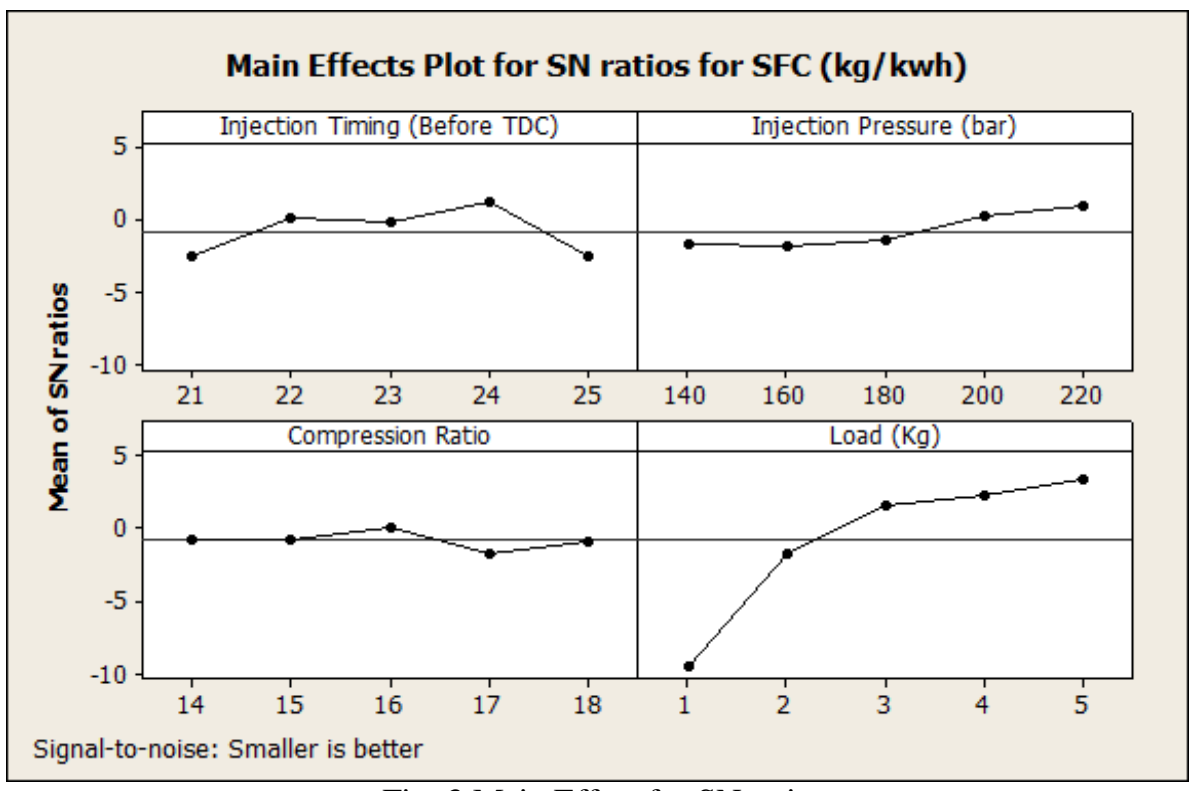

Fig. 3 Main Effect for $\mathrm{SN}$ ratio

Referring (Fig.3) the response curve for $\mathrm{S} / \mathrm{N}$ ratio, the lowest $\mathrm{S} / \mathrm{N}$ ratio was observed at injection timing (25), injection pressure(160bar) and compression ratio(17), load(1 $\mathrm{kg})$, which are optimum parameter setting for lowest Break specific fuel consumption(BSFC). From delta values as mention above, maximum (12.88876) for engine load and minimum (1.81046) for compression ratio. Parameter engine load is most significant parameter and compression ratio is least significant for Break specific fuel consumption (BSFC).

\subsection{Choosing optimum combination of parameter level}

Table.3 Response Table for Signal to Noise Ratios

\begin{tabular}{|c|c|c|c|c|}
\hline LEVEL & $\begin{array}{c}\text { INJECTION } \\
\text { TIMING BTDC }\end{array}$ & $\begin{array}{c}\text { INJECTION } \\
\text { PRESSURE }\end{array}$ & $\begin{array}{c}\text { COMPRESSION } \\
\text { RATIO }\end{array}$ & LOAD (KG) \\
\hline 1 & -2.55026 & -1.79420 & -0.76250 & -9.53682 \\
\hline 2 & 0.01307 & -1.91114 & -0.77815 & -1.69717 \\
\hline 3 & -0.15208 & -1.48479 & 0.09934 & 1.57743 \\
\hline 4 & 1.22737 & 0.15773 & -1.71111 & 2.21854 \\
\hline 5 & -2.62418 & 0.94633 & -0.93366 & 3.35195 \\
\hline Delta & 3.85155 & 2.85747 & 1.81046 & 12.88876 \\
\hline Rank & 2 & 3 & 4 & 1 \\
\hline
\end{tabular}

The term optimum set of parameters is reflects only optimal combination of the parameters defined by this experiment for lowest Break specific fuel consumption (BSFC). The optimum setting is determined by choosing the level with the highest $\mathrm{S} / \mathrm{N}$ ratio. Referring fig. 3 and table. 3 , the response curve for $\mathrm{S} / \mathrm{N}$ ratio, the highest performance at set 22 injection timing, engine load $3 \mathrm{~kg}$,injection pressure 200 bar and compression ratio 16 which is optimum parameter setting for lowest Break specific fuel consumption(BSFC).

\subsection{Predict performance at optimum setting}

\begin{tabular}{|c|c|}
\hline \multicolumn{2}{|c}{ Table.4 Optimum Output } \\
\hline S/N RATIO & $\begin{array}{c}\text { SFC } \\
\text { (KG/KWH) }\end{array}$ \\
\hline 4.29922 & 0.0436 \\
\hline
\end{tabular}

Using optimum set of parameters, which was achieved by response curve analysis was used for prediction by Minitab software. Minitab software for taguchi method of optimization was suggested specific fuel Consumption 0.0436 and $\mathrm{S} / \mathrm{N}$ ratio was 4.29922 for optimum set of parameter as shown in table 4 . 


\section{Conclusion}

The results of the taguchi experiment identifies that $22^{0}$ injection timing, injection pressure 200 bar, compression ratio 16 and engine load $3 \mathrm{~kg}$ are optimum parameter setting for lowest break specific fuel consumption. Engine performance is mostly influenced by engine load and is least influenced by Compression ratio.

\section{Acknowledgements}

It is indeed a pleasure for me to express my sincere gratitude to those who have always helped me for this paper. First I thanks to almighty god who gave strength, courage and sense to complete this paper. I am humbly expressing thanks to my respected guide Prof. Tushar M. Patel for his valuable time and constant help given to me. He provided me this opportunity to work in this inspiring project. With his enthusiasm, inspiration, and great efforts to explain things clearly and simply, he helped to make this work fun. Throughout he provided encouragement, sound advice, good teaching, good company, and lots of good ideas. I have learned many things from him such as the way of thinking and the way of conducting speech. Finally, I am thankful to all the faculty members of Mechanical Engineering Department (LDRP-ITR) and my parents, all my friends who have directly or indirectly helped me during this work.

\section{References}

[1] Dhanajay et al, Parametric optimization of single cylinder diesel engine for pyrolysis oil \& diesel blend for mechanical efficiency using taguchi method International Journal of Engineering Research \& Technology (IJERT) Vol. 1 Issue 4, June - 2012 ISSN: 2278-0181

[2] N. Maheshwari, C. Balaji*, A. Ramesh, A nonlinear regression based multi-objective optimization of parameters based on experimental data from an IC engine fueled with biodiesel blends. http://dx.doi.org/10.1016/j.biombioe.2011.02.031

[3] Karthikeyan R, Dr..Nallusamy N, Dr. Alagumoorthi N., Dr. Ilangovan V.. “ Optimization of engine operating parameters for turpentine mixed diesel fuelled DI diesel engine Using Taguchi Method". International Journal of Engineering Science and Technology. Vol. 2(10), 2010, 5295-5305

[4] Ilkilic C, "Fuel production from waste vehicle tires by catalytic pyrolysis and its application in a diesel engine", 2011, journal of fuel processing technology, 92, 1129-1135.

[5] T. Ganapathy, K. Murugesan et al, Performance optimization of Jatropha biodiesel engine model using Taguchi approach. Applied Energy 86 (2009) 2476-2486. 